\title{
FEEDBACK CONCEPTS OF DRIVER BEHAVIOR AND THE HIGHWAY INFORMATION SYSTEM*
}

\author{
HENRY S. R. KaO \\ Highway Safety Research Institute. \\ The University of Michigan, Ann Arbor, Michigan. U.S.A. \\ (Received 19 August 1968; in revised form 2 December 1968)

\section{INTRODUCTION}

THIS paper represents an effort to conceptualize human factors in dynamic driving behavior and to discuss within a systems framework the possible use of multi-channel sensory input for highway information design. Most safety research in the past has suffered from a lack of theoretical orientation which led to the isolation of systems components for experimental manipulation and observation. The background for the systems concepts and analyses of driver performance presented here is a systems integration of findings in the neuropsychology of motion and perception, human tracking behavior, biocybernetics and communication science. The individual is considered as a closed-loop feedback control system which generates a course of action and corrects the consequences by means of sensory feedback information. Within this context, driving is viewed as a closed-loop, feedback-regulated driver-vehicle-road tracking system with well-organized signal, force, spatial, temporal, and motion properties.

Highway information display is an integral part of this tracking system. Exploration of sensory modes other than vision, which are presently under-utilized, could contribute to the improvement of highway information display and driver performance.

2. DRIVING AS A CLOSED-LOOP TRACKING SYSTEM

The chief concern in highway safety is the operator's ability to position a vehicle continuously within the limits of or, ideally, in the center of the motorway. Accurate positioning depends in turn upon feedback information to the driver through most of his sensory channels about his movements, vehicle motion, and other variables in the highway environment.

To achieve optimal control in a dynamic on-the-road situation, the driver must match the sensory-motor control mechanisms involved in steering with the visual design of the vehicle body and road so that control, operator, cursor and targets are well defined for driver-vehicle-road tracking (Kao and Nagamachi, 1969a). Several concepts are essential to the consideration of steering control within this tracking framework.

\subsection{Continuity and closed-loop properties of control}

The closed-loop property in operator-highway tracking is established by a motorsensory circuit that links highway information indicators with the continuous spatial

\footnotetext{
* Preparation of this paper was supported by the Highway Safety Rescarch Institute. The University of Michigan for a project on the visual-motor feedback control in driver performance.
} 
zeroing function of vehicle movements. During highway driving, the criticality of this link increases as a function of vehicle velocity because increased velocity reduces the time constants of closed-loop control in particular instants of tracking. Evidence from manual tracking studies (Lincoln and Smith, 1952) strongly supports the importance of this feedback velocity function in driving.

Manual movements in controlling the steering wheel also assume a continuous function. Circular arm and hand movements constitute smooth and continuous rate control activities which are regulated by the continuous visual display of the course. The precision of highway driving depends on temporai and spatial refinement and coordination of such factors as visual display and motor regulation of vehicular movements; the leedback mechanism is the basis for continued performance.

\subsection{The automobile as an exoskeleton}

In driver-vehicle-road tracking, an automobile may be viewed as an exoskeletal machine and human factors in steering are defined primarily by the relations between the slave skeleton and the movements of the driver in operating controls from an internal locus. The effectiveness of machine design and driver control is determined by the dynamic space. time, force and feedback compliance of eye, head and posture movements, as well as the articulated motions of the extremities. Basic considerations in this systems view are feedback transformations between driver actions in operating the controls, and information on effects of these actions as channeled by the machine skeleton (Smith and Kao, 1968: Kao and Smith, 1969). Efficient driving performance depends upon refined driver movement to guide the skeleton in tracking a road with well-defined markings.

This concept of automobile-driver relation has its experimental-theoretic background in past research on the development of walking machines (Smith, 1963; Mosher, 1965). exoskeleton lifting machines (Smith. 1966) and external manipulators in small submersibles (Pesch, 1968a and 1968b). The design of these anthropomorphous machines has been based on the view that when the master-slave components of the machine have achieved optimal spatial, temporal. force and signal compliance with operator motion, the external skeleton can be made to perform nearly as accurately as the unaided operator. It is assumed that these control principles apply also to general driver-vehicle relationships, except that anthropomorphous vehicles transform the properties of feedback compliance between control and vehicle action in still unknown ways.

\subsection{Feedback referencing systems}

The fundamental feedback referencing system for road tracking includes five levels of information: eye movement, head movement, posture, vehicle motion and position, and the road. The zero reference for tracking is the optimal alignment of vision, head, upright sitting posture and vehicle position in relation to the road on a straight longitudinal plane. With this alignment, performance is most accurate and driver training is easiest. This is demonstrated by the ease of driving on a straight highway as compared to a curved road. and by the fact that the driver learns straight road practice earlier than other types of maneuver. For dynamic steering control, these levels of information are continuously displaced from the zero reference to a degree dependent upon road geometry, driver motor refinement through practice, and other conditions. These displacements are the driver's sensory feedback information for continuous error detection. correction, and motor control. 
The theoretical background for conceptualization of eye, head and posture as control references in driving is found in general research on human spatial orientation and behavior (Smith and Smith, 1962; Spigel, 1965; Howard and Templeton, 1966; and Freedman, 1968). Visual information from vehicle position in relation to the road has been examined in past research on the cursor-target relationship in manual tracking (Lincoln and Smith, 1952; Adams, 1961; and Poulton, 1966) and vehicle-road tracking (Gordon, 1966; Kao and Nagamachi, 1969a, 1969b).

One meaningful way of investigating this referencing system is the insertion of experimental variables between the driver and the automobile exoskeleton to measure the effects of their interactions on dynamic motor control. Sensory displacement or rearrangement of feedback information in the control process has been the most commonly used method in neuropsychological study of human perceptual and motor behavior. Some studies have dealt specifically with the effects of angular and lateral displacement of vision (Stratton, 1897; Wooster, 1923; Kohler, 1953, 1955; Werner, Wapner, Wapner and Bruel, 1953; Bossom and Held, 1957; Smith and Greene, 1963), head (Akislige, 1951; Werner, Wapner and Bruel, 1953; McFarland, Werner and Wapner, 1962) and body posture (Nystrom and Grant, 1955; Humphries, 1958; Shephard and Cook, 1959) from the straight and upright body orientation. Disturbances in performance and learning were found as a function of increased displacement.

Using the machine-exoskeleton concept, several preliminary experiments have been conducted to study the effects of lateral and angular eye-head displacements on driving accuracy (Kao, 1969; Kao and Smith, 1969). It has been shown that displacements of eye and head from the longitudinal plane of the driver's sitting position deteriorate driving performance significantly. Angular separation of eye and head results in marked deterioration in driving control.

\subsection{Sensory channels}

In all types of man-machine systems, most important sensory information is relayed through vision. Although other sensory factors are also utilized, they have not been extensively investigated. The proprioceptive and exteroceptive receptor systems supply information on such factors as tension and pressure and provide motor-generated information about movements and positions of the operator and the automobile. Sensory receptors within the vestibular organ of the labyrinth furnish continuous supplementary information on the postural movement of the operator and motion of the vehicle (Hendriksson et al., 1965). The auditory system is yet another input channel for information about such factors as tire friction with the road surface, and winds in high-speed driving. Information design should take into consideration the maximal utilization of these factors for optimal driver performance and training.

\subsection{Feedback from driver-generated vehicle movements}

A basic concept in sensory-motor behavior research is that the organism supplies itself by intrinsically-generated body movements with sensory feedback which is utilized to refine or organize the subsequent movements of the parts of the body in relation to one another and to targets or objects in the external world (Riggs et al., 1953; Held, 1961, 1965, 1968; Smith, 1966, 1967). Similarly, precision in steering performance depends on the continuous detection of driver-generated spatial displacement of the vehicle from the longitudinal reference plane. 
Besides the zeroing-in mechanism of these referencing systems for optimal steering. driver-generated spatial displacements also form the basis of other non-straight control maneuvers such as turning and backing. Continuous steering performance is maintained by initiating lateral and angular displacements of eye, head and posture in such a way as to align vehick movement and directional positioning with the new line of reference. This is seen in highway interchanges. intersection turning and backing. In steering on the road. both the zeroing reference system and displacement initiation are simultaneously integrated into the continuous feedback system for smooth and optimal road tracking. Learning to drice is a process of graduated refinement of all these levels of motor-sensory control. Compliance of these basic control mechanisms is needed in the exoskeletal automobile and roald visual design.

\subsection{Instrumemal transformation of visual- mamual control mechanisms}

Feedback concepts of sensory-motor control also emphasize the systematic transformation of real-time feedback mechanisms. In using a tool or operating a machine. an individual multiplies sources of feedback about particular responses. These levels of sensory feedback are distinguishable in the functional integration of human visual motor activities in machine and tool operation (Smith and Smith, 1966): reactive feedback, from selfgenerated body movements; instrumental feedback, received from the action of the instrument or machine: and operational feedback, received from the dynamic persisting effects of a tool-using operation on objects. materials or environmental situations. Space and time coherence of dynamic feedback from these three variable sources are key factors in motor performance.

These three feedback sources are also evident in visual manual performance within the framework of the five levels of feedback referencing for steering control. Reactive feedback is received from the driver's movements in manipulating the controls: instrumental feedback information is received from the movements of the controls, such as steering wheel. brakes. accelerator, etc., when handled by the driver. These two sources include only the motions of the human motor system and those of the vehicle. Operational leedback from the spatial relationship between the roadway and the changing vehicle position and direction forms the basis for the driver's subsequent vehicle-road tracking (Kao and Nagamachi, 1969a. 1969b). Research findings have shown visual operational information to be the most important of the three feedback factors in efficient motion regulation. No one source alone was found to be as effective as combined instrumental and operational feedback. For effective steering, the different aspects of vehicle design. road display design, and operational characteristics of control must be made coherent with the properties of motion, sensory processing and integrative action of the individual. Dynamic integration of these sources of sensory information in vehicular control is the key factor for efficient driving performance.

\subsection{Temporal fuctors}

The necessity of the real-time property for optimal performance efficiency, implies continuity of dynamic interactions between control motion and sensory feedback. Delayed visual feedback has been shown to degrade tracking efficiency (Warrick. 1949; Levine. 1953; Conklin, 1957: Smith et al., 1960: Wargo, 1967; Kao, 1968b: Coleman and Ruff, 1968). Intermittency is another form of interruption of the visual-motor feedback loop. A comparison of continuous and intermittent visual display in compensatory tracking showed 
degraded performance accuracy with intermittent display (Kao, 1968a). Other researchers have previously reported deterioration of tracking pursuit display efficiency with intermittency generated by occluding a pursuit display (Poulton and Gregory, 1952), by regulating the illuminating target frequency (Battig et al., 1955), and by converting a sinusoidal function into a series of step functions (McConnell and Shelly, 1960; Hunt, 1961 ).

As is true of all semi-automated man-machine systems, there are certain inherent transmission delays in the operation of automobiles. Feedback delay at various levels is evident in every automobile, especially in those with power steering systems. which furnish only uniform feedback information through the steering wheel so that the operator is correspondingly more dependent on visual and other sensory information to achieve equivalent steering accuracy.

Intermittency in vehicle-road tracking is comparatively unusual. High frequency vertical vibration on poorly constructed road surface is one example; dashed lane marking may be another.

Because sensory feedback is received through many channels, the effects of visual delay or intermittency may not be readily sensed by the driver in normal circumstances; but when emergencies require rapid execution of such operations as braking, acceleration or deceleration, the detrimental effects of delay or intermittency, and other physical factors may be magnified and contribute to loss of control. The extent to which sudden and momentary sensory perturbations under both delay and intermittency affect driver control has yet to be explored. Concerted effort in this direction could add significantly to understanding of both driver and machine failure in highway accidents.

\section{VISUAL FEEDBACK AND HIGHWAY INFORMATION}

In our consideration of driver behavior, it is clear that visual information display is an indispensable component of the feedback control system for road tracking, and that clarity, simplicity and overall uniformity are the basic requirements for effective road information display.

In driver-vehicle-road tracking, the design of visual information may be considered within two functional classifications of display. The information needed for immediate control and regulation of the vehicle is that providing real-time visual feedback on the spatial relations between vehicle and road, or visual display of the road surface immediately ahead of the vehicle. This constitutes the primary highway information system. Primary visual display is concerned with target or road course preview, operational feedback display, design symmetry and spatial continuity.

The second or auxiliary category of visual display is comprised of inputs which are supplementary and indirectly related to dynamic control; signing and signalling systems belong in this category.

\subsection{Primary visual display}

The most primitive information display is the construction of a shoulder adjacent to the roadway so that contrast between the two becomes the primary information for vehicle guidance and regulation. More advanced forms are the edgemarkings, lane markers, curbs, reflective raised markers, and other electronic delineation systems. From the tracking point of view, the target display, in the form of roadway edge and lane markings. is the most important primary visual information. An obscured or ill-defined target course 
leads to control confusion and deteriorated performance. For visual course-setting. roadway path anticipation, and utilization of human peripheral vision, the requirements for clear-cut roadway edge and lane division through marking, color discrimination. contrast or other modes, are necessary considerations. Studies comparing the accident rate before and after the installment of road markings in some form have shown a substantial decrease in accidents (Mills, 1958; Musick, 1960; Basile, 1962; Willey, 1965; Taylor and Foody, 1966: Taylor, 1966). Results generally support the tracking concept of driver performance in its assumption of the conduciveness to accidents of unclear delineation and a decreased accident rate after installation.

Another type of accident which may be accounted for by the need of roadway marking is the collision of vehicles moving in opposite directions. This includes $21 \cdot 0$ per cent of rural fatal accidents, and accidents caused by vehicles colliding with parked cars on the shoulder (Charlesworth, 1962).

The feedback concept of road tracking not only calls for roadway delineation in the form of complete edge and lane markings; it also emphasizes the uniformity and spatial continuity of road-course display, i.e., continuous markings throughout for both edge and lane dividers. The desirability of this is supported by several previous studies. A general tendency for drivers to search and obtain roadway guidance information from both edges of the road as well as the center marker was reported by Rowan (1963). Gordon (1966b) found the markings to be primary sources of visual information for driving. Pavement markings have been found to result in increased vehicle positioning accuracy (Williston, 1960) and driver attention and reduced visual confusion (Illinois Division of Highway, 1959).

Lane and edge markings have recently become common practice of highway design in Europe for traffic safety and flow (Summerfield, 1968).

Another consideration is the possible undesirability of intermittent markings for immediate roadway display. Dashed center lines on highways may not be as effective a visual input as continuous delineation. Dashed marking provides the driver with momentary visual information of the road at constant intervals. In visual manual tracking, numerous reports have established the validity of visual display intermittency in degrading performance accuracy (Poulton and Gregory, 1952: Battig et al., 1955; Senders, 1955; Hunt. 1961; Kao, 1968a). Because non-visual sensory channels are also involved in feeding back dynamic information of road tracking performance, the effect of intermittent roadway markings may not be easy to determine. However, under adverse weather conditions or at night, visual dependence on the forthcoming road marker for vehicle guidance mounts amazingly. This is especially significant for vehicle lateral positioning at night when the delineation is intermittent or absent (Dart, 1966). Experimental research comparing the effectiveness of continuous and intermittent visual channelization of road and their effects for improved driving control is rather limited.

Besides lane and edge delineation, ground signing in various forms is another useful method for improved primary information display. All of these may enhance the effectiveness of information input to the driver and orderly traffic flow and the traffic capacity of the road (Hale, 1960, Road Research Laboratory, 1965).

\subsection{Auxiliary visual displa!}

Vertical signing, delineators, overhead signing, luminaires and other discrete visual displays are the core of design considerations for the secondary visual information system. 
They serve primarily as visual aids in providing highway regulation, road conditions, and warning or prohibitory messages at a discrete and non-immediate level. Present consideration is directed toward basic factors affecting the design of highway signs as it involves driver cognitive behavior.

3.2.1. Development of communicative behavior. Feedback concepts interpret language development in terms of progressive changes in learning as an elaboration of the individual's symbolic control over himself, other people and environmental events. The changes in non-verbal and verbal communication throughout his life represent systematic expansion of various levels of such control of his physical and social environment: expressive movements, expressive vocalization, graphic symbols, spoken language, writing, quantative and machine communication (Smith and Smith, 1966).

Communicative behavior may be categorized as verbal or non-verbal systems representing graduated levels in the continuum from concreteness, such as expressive body movements or physical objects, to abstractness, as in words. They also roughly indicate the difference between the two systems in feedback organization and information processing.

The effectiveness of graphic and pictorial messages and written words as visual information for identification and discrimination has been extensively investigated. Irvins (1953) reported that purely verbal structures are likely to lose contact with the reality of the source of information unless they can be checked and corrected against specific events or objects in the environment. Gibson (1954) emphasized the importance of graphic stimuli or displays, saying that the realism of graphic stimuli substitutes for first hand experience and thus teaches concrete information. Smith and Smith (1966) also proposed non-verbal visual design for effective information display in terms of structuring the individual's spatial organization of his response to the environmental stimuli. Faster message transmission, accurate identification, quicker interpretation are associated with symbolic type of display. However, variations in individual ability to interpret symbols present practical difficulties in the complete utilization of such non-verbal messages (Fonseca and Kearl, 1960). A brief survey of these basic findings on communication should provide a basis for evaluating the relative effectiveness of highway signs and for designing optimal visual display.

3.2.2. Perceptual basis of highway signing system. Display signing on the highway may be divided into verbal and symbolic display designs, with a great majority possessing both. Generally, North American and Latin American countries have emphasized the verbal information system while England and the Continent have preferred graphic and pictorial display.

A brief survey of research literature on verbal and symbolic displays may provide some insights useful for a comparison of the relative effectiveness of the two systems.

The use of symbols on the highways was discussed by Eliot (1960). An early study (Lauer, 1932) on symbols showed that a graphic arrow was more effective than the printed words "right" or "left" or their abbreviations. Janda and Volk (1934), studying the sign detection time of drivers on word and arrow displays, found that an arrow alone was most effective. Words and arrow combined were second, and words alone gave the longest detection time. Levels of information abstractness may be represented by the measurement of simple reaction for concrete graphic display $(0.5 \mathrm{sec})$, choice reaction as in combined verbal and non-verbal display $(0.7-1.0 \mathrm{sec})$, and interpretation and perception time as in purely verbal information display $(2 \cdot 8-3 \cdot 2 \mathrm{sec}$ ) (Forbes, 1941). A survey (Traffic Engin- 
eering and Control, 1960) of the effectiveness of reading and interpretation of American and English sign systems with the same number of words showed much lower error scores in interpretation for English graphic signs than American verbal signs. Gray and Russell (1962) conducted a cross-cultural comparison of sign recognition. Easily interpreted symbols used on the Continent were understood by English drivers, while they had difficulty in correctly interpreting signs with more abstract symbols. Moore and Christie (1963) investigated long-range sign recognition in terms of types of signs and legibility among European. American and English signs. Representative symbols were found to be more effective than words; purely abstract symbols were least satisfactory. Ease of learning and accuracy of recognition and interpretation of symbol signs over word signs were further reported as a result of experimental research (Brainard ot al. 1961; Walker et al., 1965).

These findings strongly suggest the desirability of symbolic highway information display comparad to that based on verbal or word messages. This need is advanced especially with regard to polyglot and illiterate regions, increased international tourism, and pedestrian and motorist safety on the road. This, in addition to such factors as cultural tradition. educational level technology, and cost considerations. is still al vital areal of research effort for improvement of highway information display and traffic safety.

\section{OTHER SENSORY INPLTS AND HIIGHWAY INIORMATION}

Two non-visual sensory modes which may also be utilized for information input are the auditory system and the vestibular system in the form of vibratory sensation. While visual display may be neglected or resisted by the driver, auditory and vibratory displays are very difficult to ignore; hence, their potential use for information transmission.

\subsection{Auditory display}

Proper utilization of audio information display may be effectively approached through remote electronic sensing technology, where transmission and receiving devices are keys to the system. An unlimited number of display designs is possible for different types of information. On these lines, some efforts have been made in Japan to use electronically triggered sound signals to warn of hazardous intersections and railway crossings. This is a potentially effective balance to drivers' possible neglect of visual information. Recent developments in audio-visual sign reminding systems for highway information display and attention arousal demonstrate some of the potential applications (HRB News, 1966: DOT News, 1968: Highway Rescarch Record, 1968).

\subsection{Vibratory displa!}

The sensation of vertical body vibration is transmitted through neuroreceptors on a real-time basis. No one can possibly avoid such sensory information display. An outstanding example of this type of display in current highway information systems is the surface friction differential between the highway pavement and shoulder. A motorist mistakenly driving his car onto the roadway shoulder detects his performance error almost instantaneously and repositions his car immediately. There are a great many possibilities of vibratory display for effective message transmission and safe driving. In Japan, for example, where sharp curves, hilly slopes and other road conditions might easily induce unsafe human control and vehicle performance, raised markers are placed across the road to generate an uncomfortable sensation in the form of vertical vibration of the automobile. Design is such that motorists must slow down considerably to maintain a tolerable level 
of vehicle vibration, and no accident-conductive situations are created by the markers (Nagamachi, 1968). Similar procedures have been adopted in Italy. The same system has also been applied to railway crossings.

The recent installation in California of raised pavement markers, used as lane markers. is another example (Taylor. 1966) of vibratory display. Although designed for the purpose of avoiding undesirable weather conditions when road markers tend to be obscured. these raised markers also provide good vibratory information for safe lane changes and alerting effects in road tracking. Vibratory display poses a new area of research in highway information design for safe driving and better traffic guidance. Concerted efforts are needed among highway engineers, psychologists. and information systems experts.

\section{CONCLLLSIONS}

In the age of cybernation, we are approaching a better understanding of human beings: their behavior, their environment. and their man-made instruments for control of events in the environment. The conventional view of man as a passive respondent to environmental stimuli has made its contribution in the developmental process of behavior research. In the present era of specificity. this approach hats proved seriously inadequate in defining the basic mechanisms of behavior organization. A systems approach, based on concepts of internal control and communication in artificial and biological systems (Wiener, 1948). takes an inside-out view of environmental situations and internal-external relationships with ever-enlarging levels of control.

This paper has attempted to introduce the cybernetic ideas of self-regulation to the study of driving behavior, viewed as basically a driver-vehicle-road tracking system.

Within this structure, the properties of self-generation and regulation of vehicle movement, multi-channel sensory input, levels of feedback referencing. the automobile as slave exoskeleton. and visual-motor control mechanisms have becn suggested for dynamic driving performance.

Highway information display is believed to be maximally efficient if multi-sensory input channels are fully utilized for maximum feedback effects. The utilization of non-visual sensory modes was suggested for the design of highway information display. From a dynamic operational standpoint, highway information displays may be classified as primary and auxiliary. Primary visual display focuses on the continuous presentation of information on immediate road situations crucial for realtime driving control. Auxiliary displays are those bearing direct yet discrete messages about environmental situations which are outside of the dynamic control loop.

Overall efficiency of the operator-vehicle -road control system depends on the optimal matching of human design, vehicle design, and road design on the basis of the feedback mechanism. This paper has considered the systems interactions of driver and road designs for vehicle tracking performance.

\section{REFERENCES}

ADams. J. (1961). Human tracking behavior. Prichol. Bull. 58, 55.79

AkisLigi, Y. (1951). Experimental researchers on the structure of the perceptual space. Bull. Fac. Lit., Kyashu Liniv.

Angekmanv, H. (1967). The correct arrangement of sign posts and advance direction signs with regard to traffic. Verkehrsteichinisher Info. Austria, April. 9-15.

Bashle, A. T. (1962). Effect of pavement edge markings on traffic atcidents in Kansas. Highw. Re's. Bd. Bull. 308, $80 \cdots 86$. 
Battig, W. F., Voss. J. F. and Brogidex, W. J. (1955). Effect of frequency of target intermittence upon tracking. J. exp. Psychol. 49,244 248

Bossom, J. and HeLd, R. (1957). Shit in egocentric localization following prolonged displacement of the retinal image. Paper read to Am. Psychol. Ass.. New York.

Brainard, R. W.. Campreil., R. J. and Elkin, E. H. (1961). Design and interpretability of road signs. $J$. appl. Psichol. 45, 130- 136.

Charlesworth, G. (1962). Edge of the carriageway. Traff. Engng (ontrol 3, 103107.

Colfman, P. J. and RufF, C. (1968). Visual tracking of hand-yoked targets. Paper presented alt 12 th annual convention of the Human Factors Society. October 1968, ("hicago.

Conklin, J. E. (1957). Effect of control lag on performance in tracking task. J. cxp. Prichol. 53, 261268.

DART. O. K. (1966). A study of roadside delincator effectiveness on an interstate highway. Highw. Res. Re'. 105,2148 .

El.IOT, W. G. (1960). Symbology on highways of the world. Traff. Engng 31, 1824.

Fonste $\dot{A}$, L. and KeARl, B. (1960). Comprehension of pictorial symbols: an experiment in rural Bravil. Dept. of Agricultural Journalism. University of Wisconsin. Madison.

Forbes, T. W. (1941). Psychological applications to the new field of traffic engineering. $J .4 p p /$. Psichol. 25, 52.58. Freedman. S. (1968). Neuropsicholog!' of Spatially Oriented Behavior. Dorsey Press, Homewood.

GM experiments with new road-vehicle communications system dubbed "Dair." Highr. Res. Now Summer 1966. 33.35.

Gibson, J. J. (1954). A theory of pictorial perception. Audio-lis. Commun. Re'v. 2, 323.

Gordon, D. A. (1966a). Perceptual basis of vehicular guidance. Publ. Reds 34,3$), 5368$.

Gordon. D. A. (1966b). Experimental isolation of driver's visual input. Puhl. Rds 33, 266273.

Gray, P. G. and Russell, R. (1962). Driver's understanding of road traflic signs. The Social Survey, Central Office of Information, SS. 347. October.

Hall, F. M. (1960). Road markings as an aid to traffic movement. Traff. Engng Comtrol 9 (1), $57,58$.

HLLD. R. (1961). Exposure-history as a factor in maintaining stability of perception and coordination. $J$. nerv. ment. Dis. 132, $26 \cdots 32$.

Het D. R. (1965). Plasticity in sensory-motor systems. Scicht. Am. 213, 8494

HelD, R. (1968). Plasticity in sensori-motor coordination, Chap. 4. pp. 57 62 in Freedman S. J. ed. The Neuropirchology of Spatially Oriented Beharior. Dorsey Press. Homewood.

Hendriksson, N. G.. Nilssox, $A$. and Anderson. A. (1965). The driver as receptor of physical impulses. Imt. Rd. Saf. Traff. Rev. 37-40.

Highway Communications (1968). Highw: Res. Rec. 29, 151.

Howard. I. P. and Templeton. W. B. (1966). Human Sputial Orientation. John Wiley, Now York.

Hemphries. M. (1958). Pertormance as a function of control display relations. positions of the operator. and locations of the control. J. appl. Psychol. 42, 311 316.

Hunt. D. P. (1961). The effect of the precision of informational feedback on human tracking performance Hum. Factors 3, 7785 .

Illinois Division of Highways Traffic accident experience before and after pavement line painting. Div. of Highways. Springfield, Illinois, Ill. 6pp. (1959)

lvens, W. M.. Jr. (1953). Prims and Fisual Commumication. Routledge \& Kegan Paul. London.

Jande, H. F. and Volk, W. N. (1934). Effectiveness of various highway signs. Proc. Highu. Ros. Bd. $14,442447$.

KAO. H. S. R. (1968a). Cybernetic analysis of feedback delay and temporal intermittency in human tracking performance. Ph.D. Thesis. University of Wisconsin.

KAO. H. S. R. (1968b). Delayed visual feedback in inter-operator social tracking pertormance. Paper presented at 12th annual convention of the Human Factors Socicty. October 1968, Chicago.

KAO, H. S. R. (1969). A feedback analysis of eye-head angular displacements in human vehicular guidance. Paper to be presented at IEFE ERS International Symposium on Man-machine systems, Sept. 8 12. 1969, Cambridge. England.

KaO, H. S. R. and Naciamachi. M. (1969a). Sensory-motor feedback mechanisms in human vehicular pertormance. Ergonomics. In press.

KAO. H. S. R. and NA(iamaCHI. M. (-1969b). Visual operational feed back and design of vehicle front-end illumination for night driving performance. Percept. Mot. Skills 28, 243246.

KaO, H. S. R. and Smith, K. U. (1969). Cyhemetic television methods applied to teedback analysis of automobile safety. Nature, Lond. 222,299300 .

KoH.t:R, J. (1953). (Rehabitation in perception.) Dic Pyramide. 5, 6, \& 7. (Transiation alvailable by H. (ileitman. ed. by J. J. Gibson.)

KoHtik. I. (1955). Experiments with prolonged optical distortion. Aca. Psichol. 11, 176178.

Laule, A. R. (1932). Improvements in highway safety. Proc. Highw: Re's. Bd, 12, 389 401.

LEviNe, M. (1953). Tracking performance as a function of exponential delay between control and display. U.S.A.I. Wright Air Dev. Center. TR No. 53236. 
Lincoln, R. S. and Smith, K. U. (1952). Systematic analysis of factors determining accuracy in visual tracking. Science 116, 183-187.

MCConnell, D. and Shelly, M. W. (1960). Tracking performance on a sequence of step functions which approaches a continuous function as a limit. J. exp. Psychol. 59, 312-320.

MCFARLAND, J. J.. WAPNER, S. and Werner, H. (1962). Relation between perceived location of objects and perceived location of one's own body. Percept. Mot. Skills 15, 331-341.

Mills, J. P., Jr. (1958). Pavement edge lines on twenty-four foot surfaces in Louisiana. Highw. Res. Bd. Bull. $178,12-20$

MoORe, R. L. and Christie, A. W. (1963). Research on traffic signs, engineering for traffic conference, July 1963. pp. $113-122$.

MOSHER. R. S. (1965). Exoskeleton prototype. Technical proposal. Department of the Navy. Office of Naval Research. General Electric Co., Schenectady, N.Y.

Musick, J. V. (1960). Effect of pavement edge marking on two-lane rural state highways in Ohio. Highw. Res. Bd. Bull. 266, $1-7$

NagamaChi, M. (1968). A personal communication.

Nystrom, C. O. and Grant, D. A. (1955). Performance on a key pressing task as a function of the angular correspondence between stimulus and response elements. Percept. Mot. Skills 5, 113-125.

PesCH, A. (1968a). Human factors research and simulation in the design of small submersibles. Paper presented at 9 th annual symposium on human factors in electronics. IEEE May 1968, Washington, D.C.

Pesch, A. (1968b). Manipulation and ship control systems design for small submersibles. Paper presented at 12 th annual convention of the Human Factors Society, October 1968, Chicago.

Plan test of new system to aid stranded drivers. Dep. Transpn. News, June 6, 1968, Federal Highway Administration, Washington, D.C.

Poulton, E. C. (1966). Tracking behavior, pp. 361-410, in E. Bilodeau, ed. Acquisition of Skill, Academic Press, New York.

Poulton, E. C. and Gregory, R. L. (1952). Blinking during visual tracking. Q. Jl exp. Psychol. 4, $57-65$.

Riggs, L. A.. Ratliff, F., Cornsweet, J. C. and Cornsweet, T. N. (1953). The disappearance of steadily fixated visual test objects. J. Opt. Soc. Am. 43, 495-50l.

RoAD RESEARCH (1960). Traff. Engng. Control 2, 415

ROAD RESEARCh LABORATORY (1965), Research on Road Traffic, p. 383. D.S.I.R., London.

Rowan, N. J. (1963). Approach-end treatment of channelization: signing and delineation. Highw. Res. Rev. 31, $57-58$.

SEnders, J. W. (1955). Tracking with intermittently illuminated displays. U.S.A.F. Wright Air Dev. Center TR. 55-378, October.

ShePhard, A. H. and COOK, J. W. (1959). Body orientation and perceptual-motor performance. Percept. Mot. Skills 9, 271-280.

SMITH, K. U. (1963). Sensory feedback analysis of man-like machine systems. A new behavioral theory of human engineering. University of Wisconsin Behavioral Cybernetics Laboratory, Madison, Wisconsin.

SmiтH, K. U. (1966). Review of principles of human factors in design of the exoskeleton and four-legged pedipulator. University of Wisconsin Behavioral Cybernetics Laboratory, Madison, Wisconsin.

SmITH, K. U. and GREene, P. (1963). A critical period in maturation of performance with space-displaced vision. Percept. Mot. Skills 17, 627-639.

Smith, K. U. and Henry, J. P. (1967). Cybernetic foundations for rehabilitation. Am. J. Phys. Med. 46, 379-467.

SmITH, K. U. and KAO, H. S. R. (1968). Development of cybernetic feedback methods in driver testing, training and human factor safety research. University of Wisconsin Behavioral Cybernetics Laboratory, Madison, Wisconsin.

Sмiтн, K. U. and Smith, M. F. (1966). Cybernetic Principles of Learning and Educational Design. Holt, New York. Sмiтt, K. U. and Smith, W. M. (1962). Perception and Motion. Saunders, Philadelphia.

Smith, W. M., MCCray, J. W. and Smith, K. U. (1960). Delayed visual feedback and behavior. Science 132 , 1013-1014.

SpIGEL. I. W. (1965). Readings in the Study of Visually Perceived Movement. Harper \& Row, New York.

Stratton, G. M. (1897). Upright vision and the retinal image. Psychol. Rev. 4, 182-187.

Summerfield, K. (1968). Carriageway markings in Europe. Traff. Engng Control 9(12), 613-620.

TAYLOR, E. W. (1966). California tests raised markers as lane lines. Traff. Saf. 66, 20-21, 37-40.

TAYLOR, W. C. and FoODEY, T. U. (1966). Ohio's curve delineation program: an analysis. Traff. Engng 36, 41-45.

Walker, R. E., Nicolay, R. C. and Stearns, C. R. (1965). Comparative accuracy of recognizing American and International road signs. J. appl. Psychol. 49, 322-325.

Wargo, M. J. (1967). Delayed sensory feedback in visual and auditory tracking. Percept. Mot. Skills 24, 55-62.

WARRICK. M. J. (1949). Effect of transmission-type control lags on tracking accuracy. U.S.A.F. Air Mat. Com. Tech. Report No. 5916. 
WHR NR, H. WAPYR. S and BR(HII. J. H. (1953). Experiments on sensory-tonic tield theory of perception: VI liffect ol position of head. eyes. and that of object on position of the apparent median plane. J. exp. Prychol. 46 293299.

Whever. N. (1948) (yemetics. Wiley, New York.

WIIIFY, W. E. (1965), Arizonal dashed shoulder stripe. Trafl. Q. 9, 212.219.

Wit.istox. R. M. (1960). Lffect of pavement edge matkings on operator behavior. Highu. Res. Bd. Bull. 266, 8

Woostik. M. 11923). Certain fiators in the development of at new spatial coordination. Psychol. Monogr. 32 No, 4. 